\title{
Investigation of a Mechanism for Extraction of Organic Components of a Mineral Part From Imankara Field Oil-Bituminous Rocks by Ultrasonic Treatment Method in the Presence of Surfactants and Flocculants
}

\author{
O. K. BEYSENBAYEV ${ }^{1}$ and M. ESIRKEPOVA ${ }^{1}$ \\ M. Auezov South Kazakhstan State University, Kazakhstan, 160000, Shymkent, \\ Tauke khan avenue, 5. Kazakhstan. \\ ${ }^{*}$ Corresponding authoe E-mail: oral-kb@mail.ru \\ http://dx.doi.org/10.13005/ojc/340153
}

(Received: March 09, 2017; Accepted: June 15, 2017)

\begin{abstract}
An extraction method of oil-bituminous rocks organic component from the mineral one by ultrasonic treatment method of oil-bituminous rocks and oil products from contaminated soil using available solvents in the presence of surfactants based on a gossypol resin and polyelectrolytes - hydrolyzed polyacrylonitrile derivatives (Uniflok) has been developed. It was established that the organic component extraction rate depends not only on the ultrasonic treatment, but also on the used solvents (when using benzol, diesel fuel, kerosene, the yield composes 10-12 $\mathrm{ml}$ during 25-32 min. when using white spirit and kerosene, the yield increases in 2 times up to $18 \mathrm{ml}$ during 10-15 minutes) and concentration of added flocculent (at the concentration of $0,1 \%$ the organic component yield attains up to $18 \mathrm{ml}$ and the settling time decreases from $39-40 \mathrm{~m}^{3} \cdot 10^{-3}$ to $9 \mathrm{~m}^{3} \cdot 10^{-3}$. Results of IR-spectroscopic and electronic-microscopic studies of mineralogical composition and microstructure of oil-bituminous rocks organic and mineral components' samples show that compacting of the structure and Uniflok flocculent flocculating property, probably, occurs at the expense of adsorbed macromolecules, participating in creation of "bridging" links between particles of oil-bituminous rocks organic and inorganic components' disperse phase.
\end{abstract}

Keywords: Petroleum bituminous rocks, Surfactants, Flocculant, Organic constituents, Mineral part

\section{INTRODUCTION}

It is known that formation of oil-bituminous rocks $(\mathrm{OBR})$ is related to oil yields from subsurface layers and its impregnation of sandy and clay oils or its gathering in subdued topography in the form of oil lakes, which later were covered by sand. Besides, under the influence of such atmospheric factors as temperature, light, air, light oil components evaporated, physical and chemical

This is an $\mathbf{C}$ Open Access article licensed under a Creative Commons Attribution-NonCommercial-ShareAlike 4.0 International License (https://creativecommons.org/licenses/by-nc-sa/4.0/ ), which permits unrestricted NonCommercial use, distribution and reproduction in any medium, provided the original work is properly cited. 
properties changed, that was accompanied by increase in the oil viscosity, its oxidation and transition to natural bitumen ${ }^{1}$.

The oil-bituminous rocks, formed in a result of oil or asphalt gelation with sandy or clay materials, were got the name of the oil-bituminous rocks (OBR).

The natural bitumens are organic compounds, natural oil transformation products, having primary hydrocarbon basis, hard and viscous consistency. The natural bitumens are characterized by high concentration (sometimes up to $90-95 \%$ ) of asphaltic resinous components, by viscosity from 1-2 to $1000 \mathrm{~Pa}$, by density more than $0,965 \mathrm{~g} / \mathrm{cm}^{3}$. These natural bitumens by the properties differ from oil bitumens.

Complex geological structure of salt domes of the Caspian Sea region and anticline highs of Mangystau in combination with relative lithological poor continuity of production horizons specified extremely heterogeneous saturation of collectors by hydrocarbon fluids (from takes up to $25-30 \%$ and more) and changeability of material constitution of the last ${ }^{2}$.

It is known that OBR are multicomponent raw material, consisting of organic and mineral parts. These OBR represent a complex system and heterogeneous by the component composition.

Separation of the organic part from the mineral one is the most complex problem, as the organic component of OBR is oil-bitumen dispersed system, consisting of oils, resins and asphaltenes. Presence of resins, asphaltenes and high-molecular substances favors to formation and strengthening of intermolecular bonds and hence demonstration of adhesive properties in the system. At that, contact interaction of the mineral and organic particles strengthens. In a result of that, the separation of the organic part from the mineral one becomes a heavy task. To solve these tasks foreign and Kazakhstan scientists made a certain contribution and offered numerous separation methods of the organic part from the mineral one, using various solvents, physical actions, as well as heat treatment up to $600-650{ }^{\circ} \mathrm{C}^{3}$.
However, these methods are very complex, and require numerous energy and material costs, i.e. use of hardly accessible solvents, separation of the solvents by extraction method and vacuum drying and thermal treatment at $600{ }^{\circ} \mathrm{C}$.

\section{METHOD AND RESULTS}

Imankara field OBR were used as objects to study physical-mechanical and spectral characteristics. To solve the extraction problems of OBR organic components, an extraction method of OBR organic part from the mineral one by the method of ultrasonic treatment of OBR, as well as oil and oil products from contaminated soil using available solvents in the presence of surfactants on the basis of gossypol resin and polyelectrolytes - hydrolyzed polyacrylonitrile derivatives (Uniflok) and polyacrylamide derivatives-was developed ${ }^{4-6}$.

The developed extraction method of OBR organic part from the mineral one by the ultrasonic treatment of OBR in the presence of the surfactants and polyelectrolytes will make a certain contribution for purposeful solution of actual tasks of oilproducing branches of the Republic of Kazakhstan on generation of energy feedstock on the basis of the oil-bituminous rocks and contaminated oil containing soil. To solve the optimal conditions, the extraction of OBR organic part from the mineral one, as well as oil and oil products separation from the oil-contaminated soil were carried out as follows: Imankara field OBR or contaminated soil were dissolved in such solvents as benzol, kerosene, hexane, hexyl alcohol, diesel fuel and white spirit in ratios from $5: 1$ to $1: 5$, then these solutions were processed by the ultrasonic treatment from 2-3 min. to $6 \mathrm{~h}$ at that, it was found that optimal time of OBR solutions ultrasonic treatment composes 10-15 min. and of the contaminated soil - 2-3 minutes.

Thus, the separated organic component of OBR from the mineral one had follow-up study. Extraction methods were used to compare and prove the results, as well as to estimate efficiency of the developed extraction method of OBR organic part from the mineral one. 
The extraction was carried out by alcoholbenzol mixture $(1: 1,1: 2)$ at $80^{\circ} \mathrm{C}$ temperature, at 1 extraction stage. Content of the organic part in OBR was 13-16 mass percent.

At that, it was found that OBR organic component, the oil-bitumen dispersed system, consists of oils, resins and asphaltenes, and the separated bitumens are representative maltha. All bitumens have poor content of easily boiling (benzine) hydrocarbons, content of distillates at 200 ${ }^{\circ} \mathrm{C}$ in them composes only 4-4,5\%. Ultimate yield of light fuel cuts at $350^{\circ} \tilde{N}$ attains only 20 mass percent.

Separation of the bitumen from the bituminous rock was carried out by extraction method in soxhlet apparatus by benzol : ethanol mixture $1: 1$ to the complete discoloring of an extraction agent. The extract was centrifugalized for separation of suspended fine-dispersed clay particles. After that, the solvent was removed and unevaporated organic substance was dried at $40-50{ }^{\circ} \mathrm{C}$ in a vacuum to the stationary mass. The organic part yield composed about 15-20 mass percent of the raw feedstock ${ }^{7,8}$. Thus, the separated natural bitumens contain hetero-organic compounds of sulfur, nitrogen, oxygen, as well as vanadium, nickel.
The asphaltenes were separated from the oils and bitumen by modified hot Gold method. The feedstock charge was dissolved in 40-tuple volume of petroleum ether. The solution was held in the dark during $24 \mathrm{~h}$ at the room temperature, and then 1 hour at $50{ }^{\circ} \mathrm{C}$. The asphaltenes were washed out from the oils and resins in the Soxhlet apparatus by the petroleum ether. After the extraction, the asphaltenes were extracted from the Soxhlet apparatus by chloroform extraction, carried out till the solvent discoloring. After the chloroform stripping, the asphaltenes were dried to the stationary mass at $40-50{ }^{\circ} \mathrm{C}$ in a vacuum.

Fractional composition of OBR organic part by the boiling temperature intervals was determined according to the following procedure. OBR charge taken by a level layer in Petri dish $(25 \mathrm{~g})$ was placed in a drying oven and held under given temperature. After each hour, the test sample was cooled down and mass loss was determined. Amount of the organic part of the kir was estimated according to the mass loss. Fractional composition of Imankara field OBR organic part was determined by the following boiling temperature intervals - till 150; $150-200 ; 200-250 ; 250-350{ }^{\circ} \mathrm{C}$ (Table 1).

As is clear from Table 1 the benzene and ligroin cuts boil out till $180^{\circ} \mathrm{C}$, that corresponds to the test sample mass loss in $1,59 \mathrm{~g}$, then kerosenegasoil cuts boil out at $200-300^{\circ} \mathrm{C}\left(320^{\circ} \mathrm{C}\right)$ the mass

Table. 1: Fractional composition of Imankara field OBR organic part

Boiling temperature intervals, ${ }^{\circ} \mathrm{C}$

Cut content, \% in relation to the kir mass
Cut content, \%

in relation to the kir's organic part mass

\begin{tabular}{lcc}
\hline till 150 & 1,59 & 12,08 \\
$150-200$ & 1,52 & 11,55 \\
$200-250$ & 0,99 & 7,52 \\
$250-300$ & 0,97 & 7,37 \\
$300-350$ & 1,87 & 14,21 \\
more than 350 & 6,22 & 47,26 \\
total & 13,16 & 100 \\
according to the boiling temperatures & & \\
till 150 & 1,59 & 12,08 \\
till 200 & 3,11 & 23,63 \\
till 250 & 4,1 & 31,16 \\
till 350 & 6,94 & 52,736 \\
more than 350 & 13,16 & 100 \\
\hline
\end{tabular}


loss composed $3,48 \mathrm{~g}$, oil cuts boil out at more than $300{ }^{\circ} \mathrm{C}$ the mass loss composed $1,82 \mathrm{~g}$ and finally at more than $350{ }^{\circ} \mathrm{C}$ (paraffins, light oil cuts, intermediate and heavy oil cuts, resins, asphaltenes and carbenes) the mass loss composed 8,09 $\mathrm{g}$.

OBR mineral part study was carried out on INCA Energy (Oxford INSTRUMENTS) X-ray energydispersive microanalyzer, arranged on ISM-649LV scanning electron microscope (Table 2, Figure. 1).

OBR mineral part was previously ignited then the test area was defined, X-ray spectrum of the test area was gained. Peaks in the spectrum and its quantitative analysis were identified. The studied sample spectrum was analyzed with respect to the peaks' overlap. Element-by-element mapping by the sample surface was carried out

Table. 2: Mineralogical composition of Imankara field OBR sample

\begin{tabular}{cc}
\hline Elementary oxides & Mass percent \\
\hline $\mathrm{Na}_{2} \mathrm{O}$ & 0.782 \\
$\mathrm{MgO}$ & 2.52 \\
$\mathrm{Al}_{2} \mathrm{O}_{3}$ & 7.26 \\
$\mathrm{SiO}_{2}$ & 26.29 \\
$\mathrm{SO}_{2}$ & 5.7 \\
$\mathrm{Cl}_{2} \mathrm{O}_{7}$ & 0.47 \\
$\mathrm{~K}_{2} \mathrm{O}$ & 1.7 \\
$\mathrm{CaO}$ & 19.73 \\
$\mathrm{TiO}_{2}$ & 0.433 \\
$\mathrm{Fe}_{2} \mathrm{O}_{3}$ & 4.076 \\
\hline
\end{tabular}

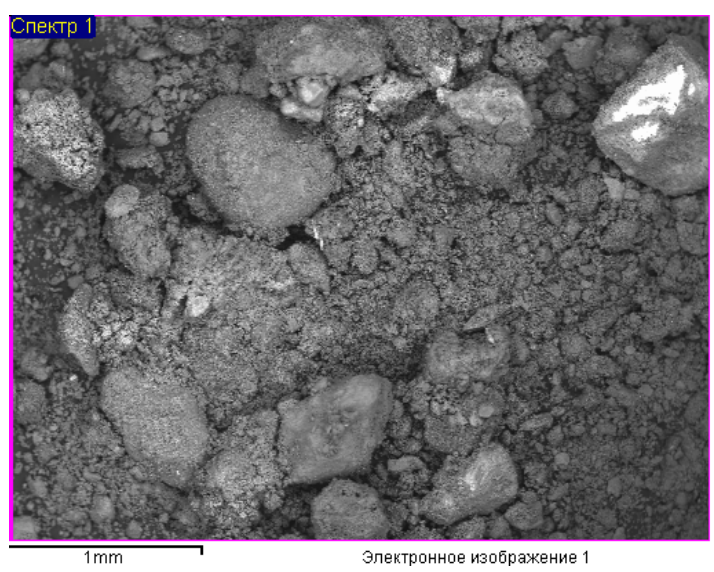

Fig. 1. OBR mineralogical composition and microstructure
(Fig. 1). By the results of spectral microanalysis it is possible to say that the sample's mineral part represents a clay material, which is presented by various silicates, carbonates, calcium, sodium and potassium ferrites, and also includes titanium dioxide, and sandy rock.

Infrared spectroscopic studies in the field of $4000-400 \mathrm{~cm}^{-1}$ were carried out on IR-Fourier spectrometer Shimadzu IR Prestige-21 with frustrated total internal reflection adapter Miracle of Pike Technologies firm for determination of OBR organic component composition.

Organic part of the natural bitumen was applied in the form of a thin film (thickness of the layer $0,03 \mathrm{~mm}$ ) on cuvettes from potassium bromide, after that, the spectrum was measured with $15 \mathrm{~mm} /$ $100 \mathrm{~cm}^{-1}$ enlargement. IR-spectrum of Imankara field OBR organic part (Fig. 2) has pronounced wave length in the fields $1300-1458 \mathrm{~cm}^{-1}, 2854-2954 \mathrm{~cm}^{-1}$, $1080.14 \mathrm{~cm}^{-1}$ and in the field $856.39 \mathrm{~cm}^{-1}$ this speaks about prevalence of deformation oscillations of $\mathrm{C}-\mathrm{H}$ compounds and violent vibrations of $\mathrm{S}-\mathrm{H}$ and $\mathrm{C}-\mathrm{H}$ types. Thus, the deformation wave oscillations $1377,17 \mathrm{~cm}^{-1}$ and $1462,04 \mathrm{~cm}^{-1}$ speak for presence of compounds with $\mathrm{CH}_{2}$-groups and $\mathrm{CH}_{3}$-groups in aliphatic chains. A broad absorption band in the field $1002 \mathrm{~cm}^{-1}-\mathrm{CH}_{2}$ - in naphthenes, as well as absorption bands $744.52 \mathrm{~cm}^{-1}, 721.38 \mathrm{~cm}^{-1}$ characteristic to $\left(\mathrm{CH}_{2}\right)_{n}$ compounds and deformation oscillations $-\mathrm{CH}=\mathrm{CH}$ - in substituted ethylene systems, are observed.

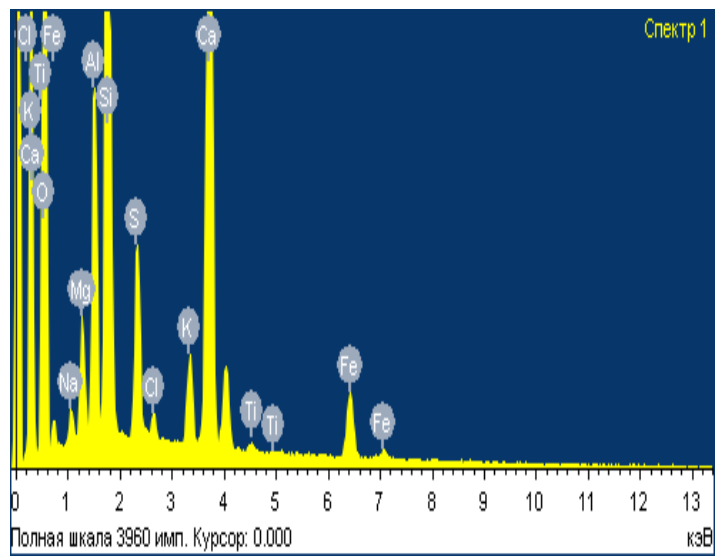




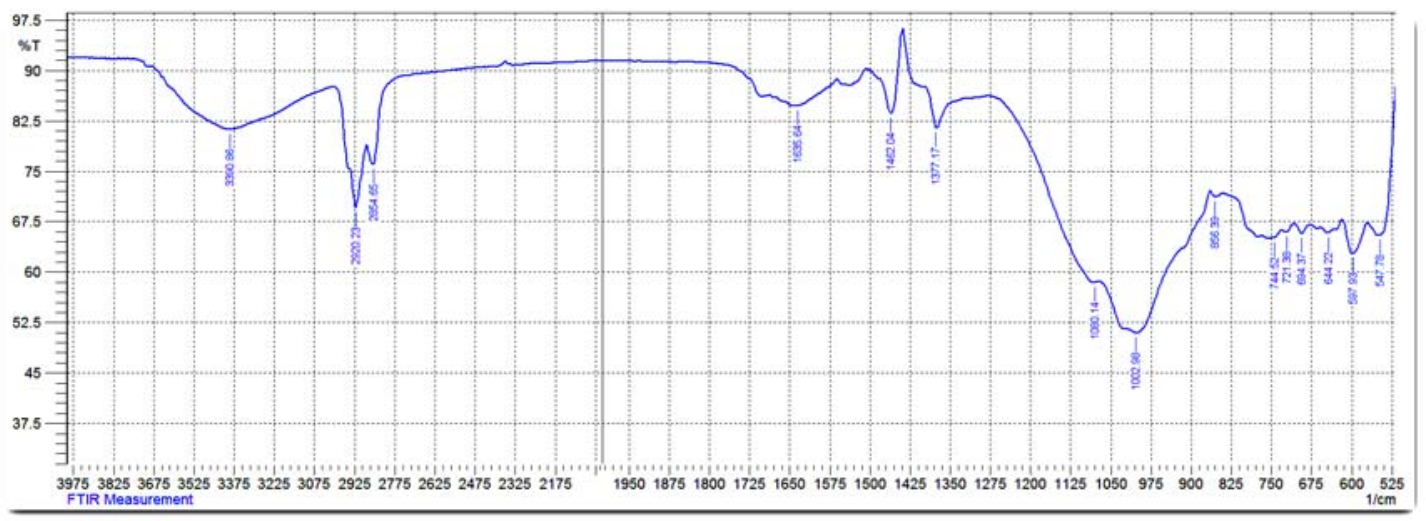

Fig. 2. Imankara field organic part IR-spectrum

The extraction rate of Imankara field OBR organic components from the mineral components was determined as follows. $95 \mathrm{ml}$ of the solution (cetone+ kerosene or hexane) of OBR was placed into glass measuring cylinders $(100 \mathrm{ml})$ before and after the ultrasonic treatment in the presence of various doses of surfactants and flocculent "Uniflok". The surfactants and "Uniflok" flocculent were added at the mixing and stepwise, i.e. at first the surfactants, then after 5-10 min. "Uniflok" flocculent. The system was mixed by ten-fold overturn of the cylinder, then after definite settling time terms. The separation of OBR organic part from the mineral one was determined by variation in a height of the deposited layer (the mineral part) and height of the liquid layer (the organic part) over the settlement $\left(\mathrm{h}_{\text {liq.layer }}\right)$, as well as relative filtration rate $\left(\mathrm{V}_{\text {rel. }}\right)$ (Table. 3$)$.

The flocculent effect was estimated by change in the settlement volume $\left(\mathrm{V}_{\text {settl. }}\right)$ in comparison with the test sample of untreated ultrasonically OBR. Functions $A V=f(C)$ have extreme character, influence of the added surfactants and flocculent, which have an effect on the process of OBR flocculation and stabilization, is apparent (Table 3).

Data on change in the settlement volume and relative filtration rate of OBR suspension depending on concentration of the added surfactants and "Uniflok" flocculent show that change in the settlement volume of OBR suspension depends on the used solvent and concentration, type of the added surfactants and flocculent, as well as settlement time.
The results of the study of Imankara field OBR organic part yield from the mineral one at the ultrasonic treatment during 10-15 minutes with 4 kw power depending on the solvents, surfactants and flocculants at a temperature of $70^{\circ} \tilde{\mathrm{N}}$ show that using benzol, diesel fuel, kerosene, the organic part yield composes 10-12 $\mathrm{ml}$ during 25-32 $\mathrm{min}$. and the mineral part yield (settlement) composes within 39$41 \mathrm{gr}$. Use of white spirit and kerosene as OBR solvent increases the organic part yield in 2 times up to $18 \mathrm{ml}$ during $10-15$ minutes.

As is clear from the Table, maximal organic part separation from the mineral one is attained during $10 \mathrm{~min}$. when using such solvents as kerosene and white spirit.

The optimum relationship of OBR and solvent composes 2:1.

The dissolved liquid settlement volume and layer height after the ultrasonic treatment after 15,20 and $30 \mathrm{~min}$. settling depending on concentration $(0,01-1,0 \%)$ of "Uniflok" flocculent were studied to estimate the separation rate of the organic component from the mineral part.

The study of change in the settlement volume (the mineral part) $\left(\mathrm{V}_{\text {settl. }}\right)$ and dissolved liquid layer height (the organic part - white spirit + kerosene) ( $\left.h_{\text {liq.layer }}\right)$ after the ultrasonic treatment depending on "Uniflok" flocculent concentration is presented in Table. 4.

When using the surfactants and "Uniflok" flocculent at $0.1 \%$ concentration, the organic part yield attains up to $18 \mathrm{ml}$ during 9 minutes. It is 
indicative of the fact that at $0.1 \%$ concentration of the surfactants and flocculent in the system, there is decrease in OBR stability by means of release of the intermolecular interactions.

In all cases when adding insignificant flocculent concentrations $(0.001-0.1 \%)$, there is the process of flocculation, that is shown by formation of more dense, relatively quickly parting settlements and high height of the liquid layer, i.e. OBR organic part.
As is clear from the Table, at low concentration of "Uniflok" flocculent in the system $(0.01-0.1 \%)$, there is decrease in OBR suspension stability, i.e. at that the dissolved liquid layer height attains up to $18 \mathrm{ml}$, settling time $9 \mathrm{~min} \cdot 10^{-3}$. A structure formation occurs at the ultrasonic treatment in the presence of the surfactants and "Uniflok" flocculent, in a result, larger aggregates, favoring to increase in the sedimentation settlement volume, are formed.

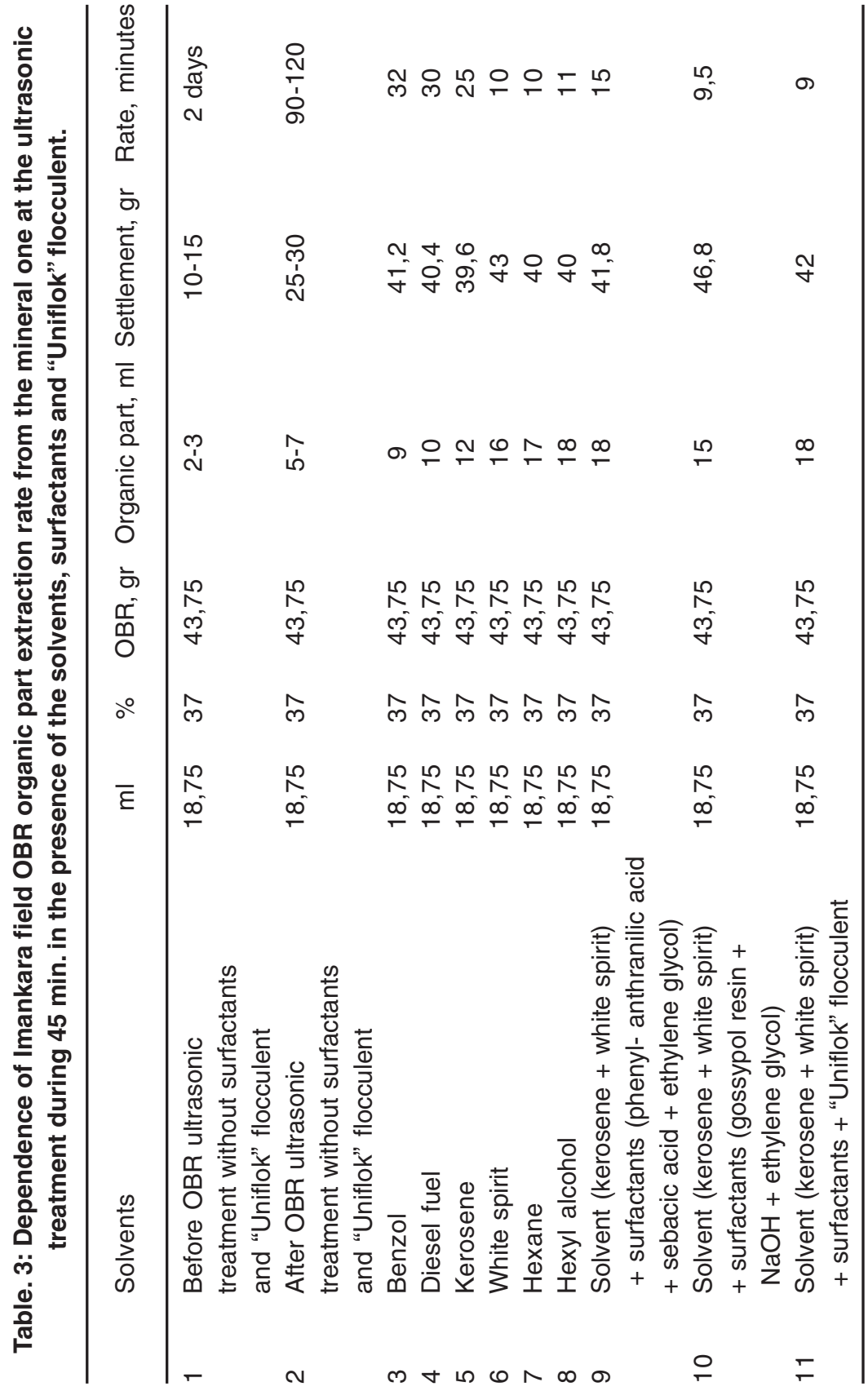


Table. 4: Change in the dissolved liquid settlement volume and layer height after the ultrasonic treatment depending on "Uniflok" flocculent concentration

\begin{tabular}{|c|c|c|c|c|c|}
\hline Uniflok concentration, C, \% & $V_{\text {settl. }}\left(m^{3 \cdot 10^{-3}}\right)$ & & & \multicolumn{2}{|c|}{$\mathrm{h}_{\text {liq.layer }}\left(\mathrm{m} \cdot 10^{-3}\right)$} \\
\hline & & 15 & 20 & 30 & \\
\hline 0 & Control & & & & \\
\hline 0,01 & 0,005 & 39,3 & 40,5 & 41,5 & 9,5 \\
\hline 0,025 & 0,0125 & 30 & 37,4 & 39,5 & 12,6 \\
\hline 0,75 & 0,0375 & 25 & 24,5 & 23,0 & 16,2 \\
\hline 0,1 & 0,050 & 9 & 10 & 9,5 & 18,0 \\
\hline 0,25 & 0,125 & 15,4 & 13,5 & 12,3 & 17,3 \\
\hline 0,5 & 0,25 & 18,5 & 19,3 & 16,8 & 15,4 \\
\hline 1,0 & 0,5 & 20,6 & 20,4 & 19,5 & 12,0 \\
\hline
\end{tabular}

\section{DISCUSSION}

The mineral part settling rate depends first of all on concentration and sizes of the formed floccule, that, in turn, depends on distance between the disperse phase particles; nature and concentration of the localized adsorption centers; density of the macromolecules' segments on the particles surface 9 . It should be noted that "Uniflok" flocculent operation in the real systems depends on a number of parameters and in the majority of cases estimation of influence of the particular factor on the resultant macroscopic binding effect is hindered. The definite content of charged groups in the macromolecules' composition and favorable conformational conditions, depending on arrangement of the functional groups, molecular mass, are necessary for optimum influence of "Uniflok" flocculent solution on OBR suspension structure. The flocculating property is not characterized by the total number of adsorbed macromolecules, however by the number of macromolecules, participating in creation of "bridging" links between two and more particles of the disperse phase ${ }^{10,11}$, as well as by the property of macroions to neutralize the disperse particles, thus decreasing kinetic system stability ${ }^{12}$.

In the result of the studies it was identified that "Uniflok" flocculent has higher flocculating effect in the studied concentration interval. The important role belongs to the concentration of the flocculent solutions, specifying OBR suspension structuring mechanism in the solutions.
When increasing the flocculent concentration in the system on $0,25 \%$ and higher, stabilization in the system appears. The further increase in "Uniflok" flocculent concentration in the system results in the stability, i.e. shows stabilizing capacity. At that, the dissolved organic component layer height decreases to $12 \mathrm{ml}$, and the settling rate increases to $20 \mathrm{~min} \cdot 10^{-3}$.

It is seen that the studied "Uniflok" flocculent solutions' effect on OBR suspension stability is explained by the sharp enough change in the conformational macromolecules state, depending on the nature, ratio and ionization of the functional groups, entered into its composition. In consequence of that, they transform to more or less folded conformation, where superiority of electrostatic mutual repulsion forces of ionized carboxylate groups over intermolecular association forces occurs. The same occurrences, apparently, are causes for formation of space network macromolecular structure in the solution, eased by the presence of the carboxylate groups, that results in the flocculating property disappearance and appearance of the studied solution' stabilizing effect on OBR suspension.

IR-spectroscopic and electronicmicroscopic studies of the samples were carried out to determine OBR organic components extraction mechanism from the mineral components after the ultrasonic treatment in the presence of the surfactants and flocculants (Figures. 3, 4, 5). 
Figures. 3, 4 show results of IR-spectra of treatment in the presence of the surfactants and OBR organic components after the ultrasonic "Uniflok" flocculent.

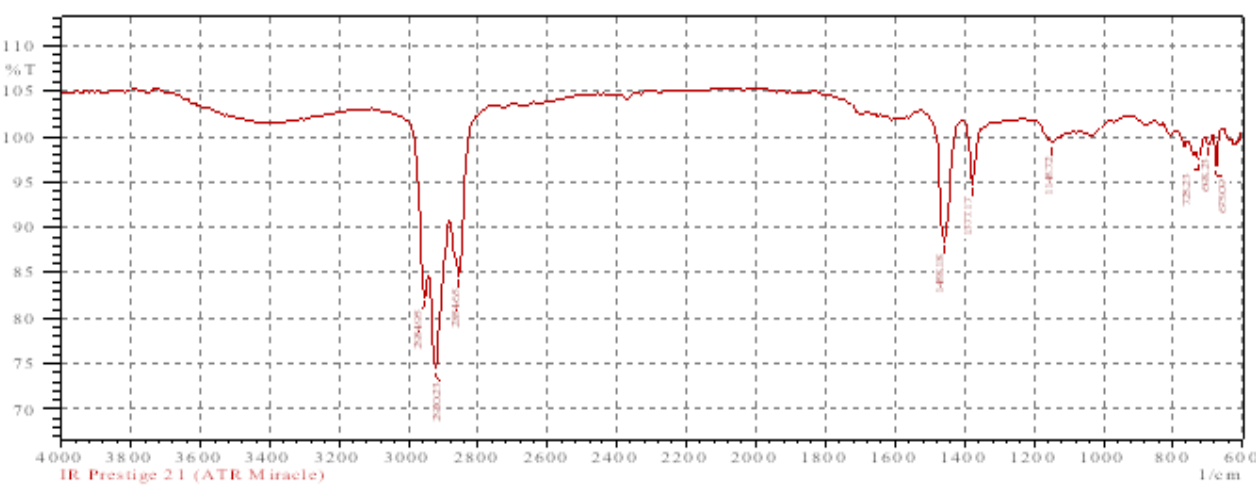

Fig. 3. IR-spectra of the sample after the ultrasonic treatment of Imankara field OBR organic part dissolved in the white spirit and kerosene $(1: 1)$ in the presence of the surfactants on the basis of gossypol resin

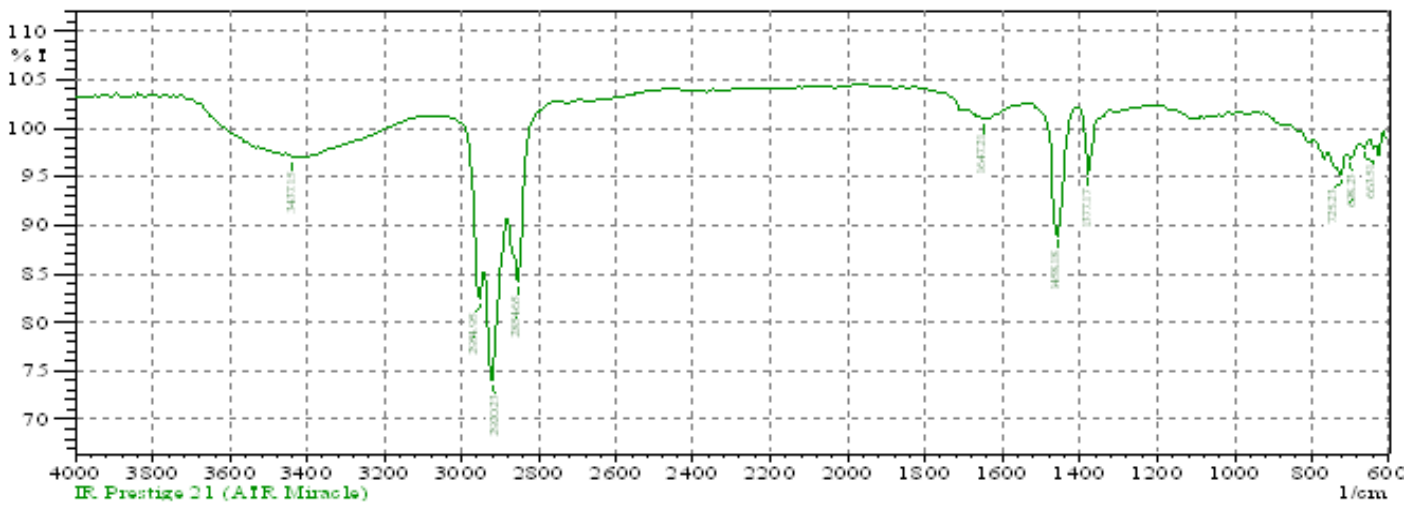

Fig. 4. IR-spectra of the sample after the ultrasonic treatment of Imankara field OBR organic part dissolved in the white spirit and kerosene $(1: 1)$ in the presence of the etherified polyacrylamide derivative flocculent

It is clear from Fig. 3, 4 that OBR organic part after the ultrasonic treatment in the presence of the surfactants and "Uniflok" flocculent suffers considerable changes, i.e. has pronounced wave lengths in the fields $1300-1458 \mathrm{~cm}^{-1}$ and $2854-2954$ $\mathrm{cm}^{-1}$ this speaks about prevalence of deformation oscillations of $\mathrm{C}-\mathrm{H}$ compounds and violent vibrations of $\mathrm{S}-\mathrm{H}$ and $\mathrm{C}-\mathrm{H}$ types. Thus, the deformation wave oscillations $1377,13 \mathrm{~cm}^{-1}$ and $1458,18 \mathrm{~cm}^{-1}$ speak for presence of compounds with $\mathrm{CH}_{2}$-groups and $\mathrm{CH}_{3}$-groups in aliphatic chains, and bands of 2854 and $2954 \mathrm{~cm}^{-1}$ are characteristic to aliphatic oil product compounds with groups of C$\mathrm{CH}_{3}$ bonds. Lengths of waves of $675-725 \mathrm{~cm}^{-1}$ are characteristic to the deformation oscillations $-\mathrm{CH}=\mathrm{CH}$ - in the substituted ethylene systems.

Comparisons of IR-spectra of Imankara field OBR organic component before (Fig. 2) and after the ultrasonic treatment in the presence of "Uniflok" flocculent (Fig. 4) show a shift of the broad absorption band with peaks of $3390.86 \mathrm{~cm}^{-1}$ (feedstock) to the side of $3437.15 \mathrm{~cm}^{-1}$. It is explained by probability of forming the intermolecular hydrogen bond between OBR and "Uniflok" flocculent amide group. There is also enhancement of the absorption band in the field of $1145.72 \mathrm{~cm}^{-1}$ characteristic for $\mathrm{C}-\mathrm{H}$ bond of unsaturated aliphatic acids of the used surfactants based on the gossypol resin (Fig. 3) and appearance of a shoulder in the field of $2954.95 \mathrm{~cm}^{-1}$ providing enhancement of $-\mathrm{CH}_{3}$ bond (Figure 3, 4).

Mineralogical composition and microstructure of Imankara field OBR suspension sample dissolved in the white spirit after the ultrasonic treatment are shown in Table. 5. As is clear from Table. 5 and Fig. 5 it is seen that the 
mineralogical sample structure is characterized by separate gatherings of mechanical components in the organic solution. Considerable proportion of the mineral component $(\sim 40 \%)$ is presented by minerals of calcium and silicon ferrites $\left(\mathrm{CaO}, \mathrm{Fe}_{2} \mathrm{O}_{3}\right.$ $\mathrm{Fe}_{2} \mathrm{O}_{3} \cdot \mathrm{SiO}_{2}$ ) of irregular shape reddish-black crystals. Aluminosilicate component minerals are characterized by pseudohexagonal and tabular structures, mostly of vermicular forms, usually colorless or rarely greenish in the solid masses $(\sim 40 \%)$. Intermediate minerals are insignificant inclusions of sulfate calcium and magnesium compounds, determined by surrounded structure of tabular prolate forms with colorless or bright blue color ( 20\%).

Table. 5: Mineralogical composition of Imankara field OBR suspension sample dissolved in the white spirit after the ultrasonic treatment

Element Mass percent Oxides Mass percent

\begin{tabular}{lclc}
\hline & 48,28 & - \\
$\mathrm{Na}$ & 0,76 & $\mathrm{Na}_{2} \mathrm{O}$ & 1,024 \\
$\mathrm{Mg}$ & 0,99 & $\mathrm{MgO}$ & 1,64 \\
$\mathrm{Al}$ & 5,30 & $\mathrm{Al}_{2} \mathrm{O}_{3}$ & 10,01 \\
$\mathrm{Si}$ & 8,16 & $\mathrm{SiO}_{2}$ & 17,45 \\
$\mathrm{P}$ & 0,23 & $\mathrm{P}_{2} \mathrm{O}_{5}$ & 0,526 \\
$\mathrm{~S}$ & 3,07 & $\mathrm{SO}_{2}$ & 3,13 \\
$\mathrm{~K}$ & 0,98 & $\mathrm{~K}_{2} \mathrm{O}$ & 1,18 \\
$\mathrm{Ca}$ & 2,84 & $\mathrm{CaO}$ & 3,97 \\
$\mathrm{Ti}$ & 0,21 & $\mathrm{TiO}_{2}$ & 0,35 \\
$\mathrm{~V}$ & 0,22 & $\mathrm{~V}_{2} \mathrm{O}_{5}$ & 0,34 \\
$\mathrm{Mn}$ & 0,19 & $\mathrm{MnO}^{2}$ & 0,27 \\
$\mathrm{Fe}$ & 28,38 & $\mathrm{Fe}_{2} \mathrm{O}_{3}$ & 40,58 \\
$\mathrm{Ni}$ & 0,14 & $\mathrm{NiO}_{4}$ & 0,24 \\
$\mathrm{Zn}$ & 0,25 & $\mathrm{ZnO}^{2}$ & 0,31 \\
\hline
\end{tabular}

microstructure of Imankara field OBR suspension sample dissolved in the white spirit and kerosene after the ultrasonic treatment in the presence of the surfactants are shown in Table 6 and Figure 6. As is clear from Table 6 and Figure 6 it is seen that the mineralogical sample structure is characterized by prevalence of separate gatherings of sulfate iron and sodium salt components. Gathered sodium feldspar is characterized by colorless tabular crystals, often of irregular prismatic form. Dark gatherings are characteristic for sulfate and oxide iron minerals, mostly of black color and dense structure.
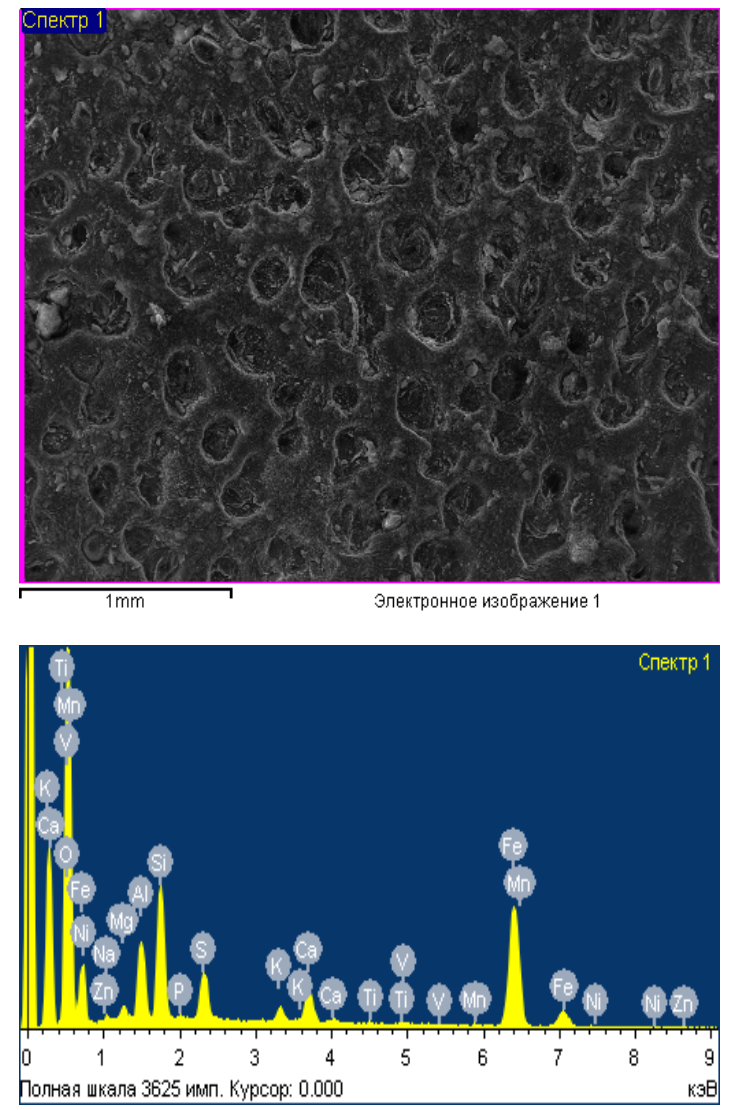

Fig. 5. Mineralogical composition and microstructure of Imankara field OBR suspension sample dissolved in the white spirit after the ultrasonic treatment

Table. 6: Mineralogical composition of Imankara field OBR suspension sample dissolved in the white spirit and kerosene after the ultrasonic treatment in the presence of the surfactants.

Element Mass percent Oxides Mass percent

\begin{tabular}{lccc}
\hline $\mathrm{O}$ & 43,67 & & - \\
$\mathrm{Na}$ & 23,14 & $\mathrm{Na}_{2} \mathrm{O}$ & 31,19 \\
$\mathrm{Mg}$ & 0,56 & $\mathrm{MgO}$ & 0,928 \\
$\mathrm{Al}$ & 2,58 & $\mathrm{Al}_{2} \mathrm{O}_{3}$ & 4,87 \\
$\mathrm{Si}$ & 3,91 & $\mathrm{SiO}_{2}$ & 8,36 \\
$\mathrm{~S}$ & 14,91 & $\mathrm{SO}_{2}$ & 15,20 \\
$\mathrm{~K}$ & 0,60 & $\mathrm{~K}_{2} \mathrm{O}$ & 0,723 \\
$\mathrm{Ca}$ & 1,22 & $\mathrm{CaO}$ & 1,706 \\
$\mathrm{~V}$ & 0,18 & $\mathrm{~V}_{2} \mathrm{O}_{5}$ & 0,88 \\
$\mathrm{Mn}$ & 0,12 & $\mathrm{MnO}$ & 0,17 \\
$\mathrm{Fe}$ & 9,12 & $\mathrm{Fe}_{2} \mathrm{O}_{3}$ & 13,04 \\
\hline
\end{tabular}



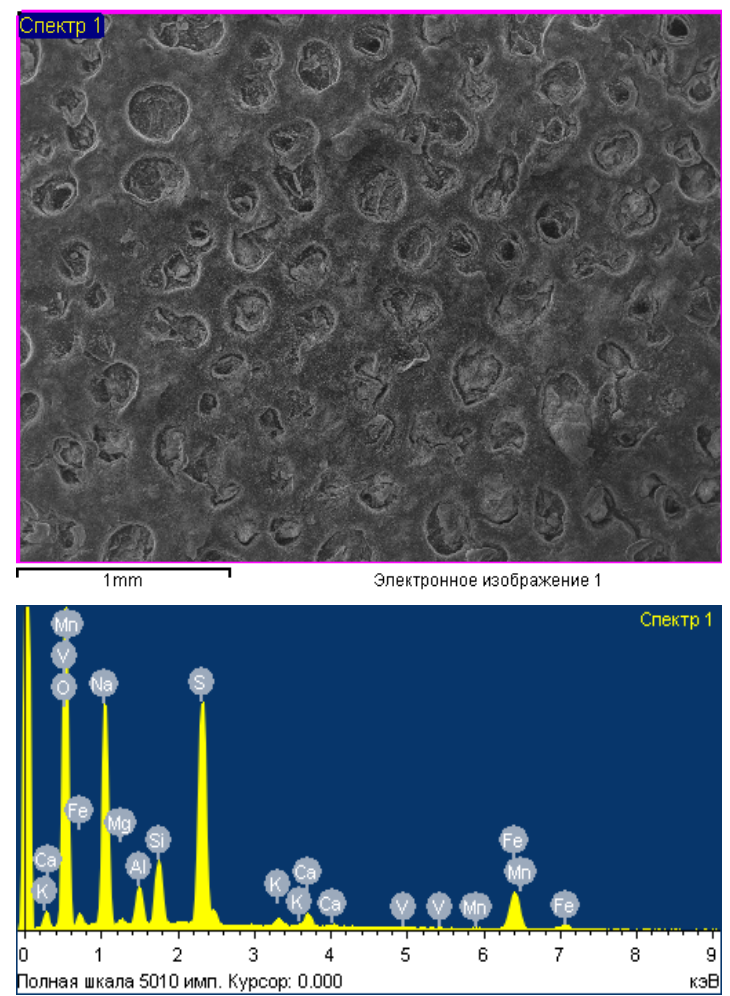

Fig. 6. Mineralogical composition and microstructure of Imankara field OBR suspension sample dissolved in the white spirit and kerosene after the ultrasonic treatment in the presence of the surfactants

Mineralogical composition and microstructure of Imankara field OBR suspension sample dissolved in the white spirit and kerosene after the ultrasonic treatment in the presence of "Uniflok" flocculent are shown in Table 7 and Figure 7. As is clear from Table 7 and Figure 7 it is seen that the studied sample is characterized by the definite pronounced gatherings of OBR mineral components, mostly in the form of crystals of sodium feldspar and sulfate iron compound with calcium inclusions ( 50-10\%). The sodium feldspar crystal structure is characterized by colorless tabular or irregular prismatic crystals. Sulfate and ferrite components are presented by dark dense structure of reddish and black gatherings. Some silicatealuminate minerals of kaolinite in the gatherings are characterized by curved crystals.

Thus, the study of the mineralogical composition and microstructure of Imankara field OBR suspension sample dissolved in the white spirit and kerosene after the ultrasonic treatment in the presence of the surfactants and "Uniflok" flocculent also proves occurrence of the crystallization structure and prevalence of the system of mostly dense black color structure.

Table. 7: Mineralogical composition of Imankara field OBR suspension sample dissolved in the white spirit and kerosene after the ultrasonic treatment in the presence of "Uniflok" flocculent.

\begin{tabular}{lccc}
\hline Element & Mass percent & Oxides & Mass percent \\
\hline $\mathrm{O}$ & 43,38 & & - \\
$\mathrm{Na}$ & 15,72 & $\mathrm{Na}_{2} \mathrm{O}$ & 21,19 \\
$\mathrm{Mg}$ & 0,93 & $\mathrm{MgO}$ & 1,54 \\
$\mathrm{Al}$ & 3,45 & $\mathrm{Al}_{2} \mathrm{O}_{3}$ & 6,52 \\
$\mathrm{Si}$ & 4,04 & $\mathrm{SiO}_{2}$ & 8,64 \\
$\mathrm{~S}$ & 10,65 & $\mathrm{P}_{2} \mathrm{O}_{5}$ & 10,86 \\
$\mathrm{~K}$ & 0,65 & $\mathrm{SO}_{2}$ & 0,78 \\
$\mathrm{Ca}$ & 1,71 & $\mathrm{CaO}^{2}$ & 2,4 \\
$\mathrm{Ti}$ & 0,15 & $\mathrm{TiO}_{2}$ & 0,25 \\
$\mathrm{~V}$ & 0,40 & $\mathrm{~V}_{2} \mathrm{O}_{5}$ & 0,62 \\
$\mathrm{Mn}$ & 0,33 & $\mathrm{MnO}^{2}$ & 0,46 \\
$\mathrm{Fe}$ & 18,30 & $\mathrm{Fe}_{2} \mathrm{O}_{3}$ & 26,16 \\
& & & \\
\hline
\end{tabular}
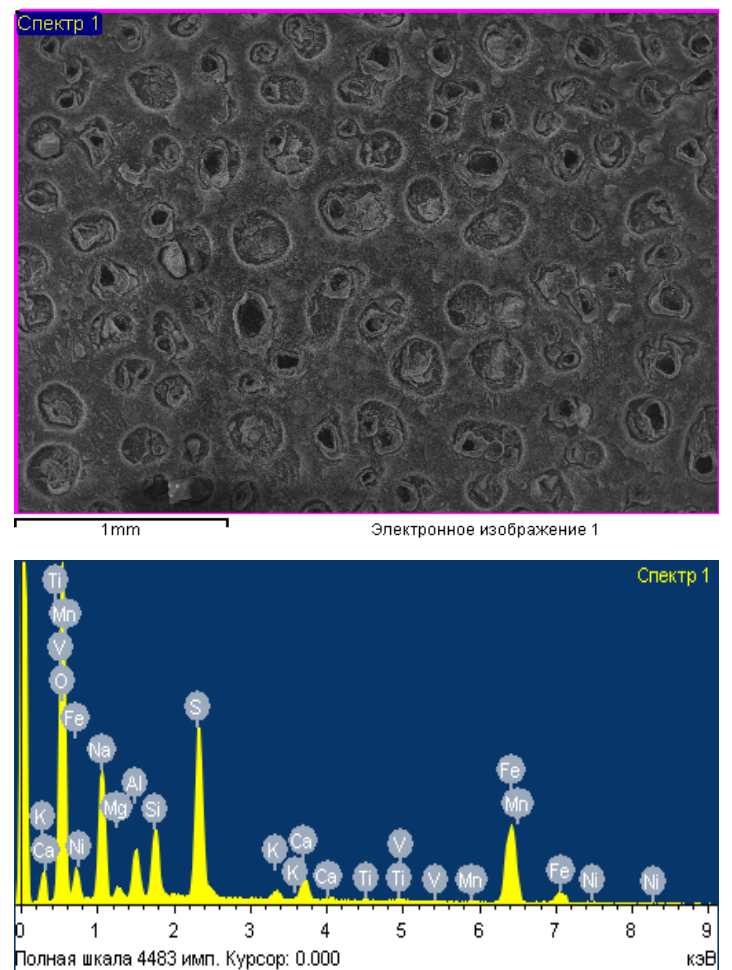

Fig. 7. Mineralogical composition and microstructure of Imankara field OBR suspension sample dissolved in the white spirit and kerosene after the ultrasonic treatment in the presence of "Uniflok" flocculent 


\section{CONCLUSION}

The extraction method of OBR organic component from the mineral one by the ultrasonic treatment method of OBR, as well as oil and oil products from the contaminated soil using available solvents in the presence of the surfactants based on the gossypol resin and polyelectrolytes hydrolyzed polyacrylonitrile derivatives (Uniflok) has been developed.

The organic component extraction rate and Imankara field OBR mineral part settlement volume change before and after the ultrasonic treatment in the presence of the solvents, surfactants based on the gossypol resin and polyelectrolytes - hydrolyzed polyacrylonitrile derivatives (Uniflok) have been studied. At that, it has been established that the organic component extraction rate depends not only on the ultrasonic treatment, but also on the used solvents (when using the benzol, diesel fuel, kerosene, the yield composes 10-12 ml during 25-32 minutes, when using the white spirit and kerosene, the yield increases in 2 times up to $18 \mathrm{ml}$ during 10-15 min.) and concentration of the added flocculent (at the concentration of $0,1 \%$ the organic component yield attains up to $18 \mathrm{ml}$ and the settling time decreases from $39-40 \mathrm{~m}^{3} \cdot 10^{-3}$ to $9 \mathrm{~m}^{3} \cdot 10^{-3}$ ).

IR-spectroscopic and electronicmicroscopic studies of the mineralogical composition and microstructure of Imankara field OBR organic and mineral components before and after the ultrasonic treatment in the presence of the solvents, surfactants based on the gossypol resin and polyelectrolytes - hydrolyzed polyacrylonitrile derivatives (Uniflok) speak for formation and compacting of the structure. At that, compacting of the structure and Uniflok flocculent flocculating property, probably, occurs at the expense of the adsorbed macromolecules, participating in creation of "bridging" links between particles of the disperse phase of OBR organic and inorganic components. It should be noted that the role of the surfactants at the initial stage comes to OBR solution dispersion and recrystallization for weakening of the intermolecular bonds of paraffins, asphaltenes, resins and macromolecular compounds.

\section{REFERENCES}

1. Nadirov N.Ê., Abdikarimov M.N., Bakesheva S.B. New bituminous materials., Tauar., 2001, 3, 39.

2. Nadirov N.Ê., Brown A.Ye., Trokhimenko M.S., all. Oil-bituminous rocks of Kazakhstan: problems and perspectives., Alma-Ata: Science, 1985, 376.

3. Turgumbayeva R.Kh., Nadirov N.Ê., Abdikarimov M.N. Pre-patent 17206 RK. $\mathrm{MPK}^{7}$ Â01D 11/00. Equipment for bitumen separation from oil-bituminous rocks. Bulletin., 2006, 4.

4. Makhashov Ye.Zh., Beisenbayev î.Ê., Assanov À.À. Some colloidal-chemical properties of water soluble copolymers of acrylamide and Na-furamates Bulletin of Yassawi University. Turkestan: IKTU., 1997, 49-51.

5. Beisenbaev O.K., Isa A.B., Kovaleva A.E. Research of polyacrylonitrile saponification heterophase process mechanismin different conditions. Orient. J. Chem., 2015,31(4).2291-2301

6. Weitzer Yu.M., Mints D.M. High molecular flocculants in purification processes of natural and waste waters. M.: Stroyizdat., 1984, 201.

7. Kaldygozov E. K., etc. Oxidation of tar from petrobituminous rocks., / Thesis of reports of RNTK. Scientific and technical progress and ecology/, Aktau., 1992, 132.

8. Kaldygozov E. K., etc. Oxidation of tars of the West Siberian and Kumkol oil in mix with tar of petrobituminous rocks / B. U. The deposited manuscripts. ÊazNIIÒI. Almaty., 1994, 3, 33.

9. Baran À.À. Polymer-containing disperse systems, Kiev: Naukova dumka., 1986, 203.

10. Beisenbaev O.K., Ilyasova K.U., Makhashov Ye.Zh. RK patent No. 12401. Powdered hydrolyzed polyacrylonitrile preparation method. Published in bulletin., 2006, 7.

11. Zapolsky L.K., Baran À.À. Coagulants and flocculants in water purification processes., L.: Chemistry., 1987, 208.

12. Khamrayev S.S. Flocculation of mineral dispersions, Uzb. Chemical Journal., 1999,24-30. 